\title{
EL IMPRESIONISMO MUSICAL EN TRES OBRAS PARA PIANO DE COMPOSITORES ESPAÑOLES: VICENTE ARREGUI (1902), SALVADOR BACARISSE (1922) Y JOAQUÍN TURINA (1930)
}

Christiane HEINE

\begin{abstract}
The analysis of three works for piano by Vicente Arregui (Sonata en fa menor), Salvador Bacarisse (Heraldos) and Joaquín Turina (Sonata fantasía) demostrates that in Spain french musical impressionism wasn't only a transitory movement of the early 20th century, because its stylistic peculiarities influenced the technique of composition of at least two generations of spanish musicians. Based on the examination of sonorous and melodic procedures, this article commences with a study of the most characteristic stylistic criteria of musical impressionism in order to reveal their assimilation in the style of each of these composers.
\end{abstract}

\section{Resumen}

El análisis de tres obras para piano de Vicente Arregui (Sonata en fa menor), Salvador Bacarisse (Heraldos) y Joaquín Turina (Sonata fantasía) demuestra que el impresionismo musical francés en España no fue una mera corriente pasajera de principios del siglo xx porque sus peculiaridades estilísticas influyeron durante tres décadas en la técnica de composición de al menos dos generaciones de músicos españoles. Basado en el examen del tratamiento sonoro y melódico, el estudio parte de los criterios estilísticos más característicos del impresionismo musical para relevar a continuación su asimilación al estilo de cada uno de estos compositores.

\section{Introducción}

\section{España y el impresionismo musical}

El cambio de conciencia que, suscitado por el fracaso político de 1898, se implantó a finales del siglo XIX entre los intelectuales españoles, fue decisivo para la apertura de España hacia el resto de Europa. Si bien se había estancado la evolución de la música española a raíz del aislamiento cultural, ahora los compositores intentaron la conexión con Europa y especialmente con Francia. Es sintomático que la recepción de la nueva música francesa se realizara en primer lugar fuera de la península, en Francia, donde Isaac Albéniz, Joaquín Turina y Manuel de Falla, a causa 
de su prolongada estancia en aquel país, ${ }^{1}$ se pusieron al corriente de las innovaciones musicales de la época.

Para su futuro desarrollo artístico fue decisivo su encuentro con la música de Claude Debussy bajo cuya influencia se realizó la transformación de la música española caracterizada en sus comienzos por las técnicas de composición impresionistas.

El retorno de Turina y Falla a España supuso para la vida musical de Madrid, donde ambos se instalaron en 1914, una eminente animación, y la influencia francesa no quedó sin consecuencias en la joven generación.

Según el ejemplo francés fue fundada en 1915 la Sociedad de Música, el mismo año en que se constituyera, bajo la dirección del compositor Bartolomé Pérez Casas, la Orquesta Filarmónica que se sostuvo al lado de la Orquesta Sinfónica creada ya en 1904 y dirigida por Enrique Fernández Arbós. Ambas orquestas desempeñaron en la capital un papel importante en la difusión de la nueva música francesa: destacan las primeras audiciones del Prélude à l'après midi d'un faune en 1906 (estreno 1894), y Nocturnes en 1908 (estreno 1900) a través de la Orquesta Sinfónica, y en la temporada de 1915 a 1917 la interpretación por la Orquesta Filarmónica de La mer (estreno 1905) además de Le martyre de Saint Sébastian (estreno 1911) y La demoiselle élue (estreno 1893) en la temporada siguiente. Estas actividades culminarían en la primavera de 1920 en seis conferencias organizadas por el Instituto Francés y dadas por George Jean-Aubry sobre la nueva música francesa, cuya importancia se debe a la colaboración de Falla como intérprete de algunas obras pianísticas de Debussy. ${ }^{2}$ Además, los tres conciertos ofrecidos por la Orquesta Sinfónica en 1920 con motivo de la «Semana francesa», celebrada en Madrid, estaban exclusivamente dedicados, a iniciativa personal de Arbós, a la música francesa. ${ }^{3} \mathrm{El}$ punto final de esta introducción de la nueva música francesa en España puso el estreno madrileño de Iberia de Debussy en enero de 1921 que causó una auténtica batalla entre el público presente. ${ }^{4}$

\section{Arregui, Turina, Bacarisse: sus relaciones con Francia}

Las tres obras impresionistas que se estudian a continuación proceden de compositores españoles pertenecientes a dos generaciones musicales distintas: Vicente Arregui (1871-1925) y Joaquín Turina (1882-1949) representan, según la clasificación de Tomás Marco, la «Generación de los maestros», ${ }^{5}$ mientras que Salvador Bacarisse (1898-1963) contaba entre los miembros del madrileño «Grupo de los ocho» de la llamada «Generación del 27». ${ }^{6}$

1. Albéniz se había instalado en París en 1893. Le siguieron Joaquín Turina en 1905 y Manuel de Falla en 1907, quienes regresaron a España en 1914 al estallar la Primera Guerra Mundial.

2. Salazar, Adolfo. «Las conferencias en el Instituto Francés.» El Sol, 18-IV-1920.

3. [SAlazAR]. "Amistad francoespañola. Semana francesa en Madrid.» El Sol, 18(?)-V-1920.

4. Salazar. "Le tombeau de Debussy". - "Iberia" y la Orquesta Filarmónica.» El Sol, 25-I-1921.

5. Marco, Tomás. Historia de la música española. 6. Siglo XX. Madrid: Alianza Editorial, S. A., 1983. Cap. 3: «Los maestros», pp. 39-66. Cap. 4: «La Generación de los maestros», pp. 67-86.

6. Heine, Christiane. Salvador Bacarisse (1898-1963). Die Kriterien seines Stils während der Schaffenszeit in Spanien (bis 1939). Frankfurt: Peter Lang, 1993. 
Destaca que la influencia que la nueva música francesa tuvo en los dos primeros fue directa, debido a la estancia de ambos en París: Arregui se encontró, gracias a una beca de la Real Academia de Bellas Artes de San Fernando, ya en 1902 en la capital francesa, donde compuso la Sonata en fa menor para piano, cuyo primer movimiento es objeto de este estudio. La estancia de Turina en París se prolongó durante casi una década, por lo cual no extraña que la influencia impresionista en este compositor es más tenaz que en los otros dos, dejando huella aún en su obra tardía, como es el caso de la Sonata fantasía de 1932 cuyo tiempo inicial se analizará a continuación.

Al contrario de estos dos músicos que a principio del siglo xx vivieron la corriente impresionista de manera directa, el representante de la generación musical siguiente, Bacarisse, pese a sus raíces francesas, ${ }^{7}$ no viajó en ninguna ocasión por motivos artísticos a París, si bien al terminar la Guerra Civil se vio obligado a emigrar a Francia, donde residió hasta su muerte. No obstante, sus primeras composiciones, que coincidieron con la fase final de la recepción del impresionismo en España, se encuentran bajo influencia francófila, aunque sus estudios con Conrado del Campo hagan esperar más bien una orientación hacia la polifonía de éste, basada en Richard Wagner y Richard Strauss y caracterizada por el colorido nacionalista. Bacarisse reveló en una entrevista de 1959 que durante toda su vida había sentido una gran admiración, un «fervor sin límites» por Debussy y que en sus comienzos, principalmente al componer en 1922 el poema sinfónico La nave de Ulises (op. 1) y Heraldos para piano (op. 2a), en que estriba el siguiente estudio, se consideraba «discípulo espiritual» del compositor francés. ${ }^{8}$

\section{Análisis}

1. Arregui: Sonata en fa menor; Bacarisse: Heraldos; Turina: Sonata fantasía

Las tres obras analizadas a continuación abarcan las tres primeras décadas del siglo xx y marcan diferentes épocas en la producción de cada compositor.

Tanto Arregui como Bacarisse, con veinte años de diferencia, estaban al comienzo de su prometedora carrera artística cuando compusieron sus respectivas obras para piano. Tienen en común no solamente una formación musical procedente del conservatorio de Madrid así como un reconocimiento relativamente temprano, premiado con dos becas en el caso de Arregui ${ }^{9}$ y con el Premio Nacional en caso de Bacarisse,$^{10}$ sino también llama la atención la particularidad de que en el catálogo de obras de ambos la música para piano constituye más bien un género accidental frente a los géneros de gran plantilla. ${ }^{11}$

7. El padre de Bacarisse, Sauveur Edmond Bacarisse, procedió del pueblo pirenaico-francés Garlin.

8. Bacarisse, Salvador. "Coloquios con Salvador Bacarisse (II)». Entrevista de Julián Antonio Ramírez en Radiodiffusion Télévision Française, París, transmitida el 17-III-1959.

9. 1899 para Roma; 1902 para París.

10. En 1923 para op. 1.

11. En Arregui predomina la música escénica y en Bacarisse la música orquestal en general. 
A diferencia de estos dos compositores, Turina, a partir de 1931 designado catedrático de composición en el Conservatorio Superior de Madrid, estaba en plena madurez cuando compuso su Sonata fantasía op. 59, que forma parte de un extenso catálogo de obras para piano solo, el cual tiene su razón en la larga trayectoria pianística del compositor.

La Sonata en fa menor de Arregui consta de tres movimientos que, al contrario de lo destacado por Henri Collet, ${ }^{12}$ prescinden de relaciones cíclicas de índole tonal como diastemático-rítmico además de carecer de coherencias en cuanto al lenguaje musical y a las técnicas de composición, con lo cual se deduce que se trata de una yuxtaposición de tres piezas individuales, escritas probablemente con una cronología opuesta a la que presenta la primera edición en $1923 .{ }^{13}$ El tercer movimiento, Allegro assai con fuoco (do menor), es el más convencional de la obra debido a su lenguaje romántico en que destacan tanto la elaboración motívica como la funcionalidad armónica frente al coetáneo tratamiento melódico y sonoro que reina en el primer tiempo. Su estructura formal, a pesar de pronunciarse dos temas con una relación tonal de quinta - aunque inferior (do menor/mayor - fa mayor) - y de existir una parte central con función «modulante» y «desarrollante», es un ejemplo de sonata «defectuosa», puesto que la relación de Subdominante entre las dos principales secciones temáticas, que ya por sí supone una disminución de la habitual tensión armónica, se mantiene, en contra a la idea principal de la forma sonata, en la «reexposición» (cc. 162-208) que es una repetición literal de la primera parte (suprimidos los primeros 23 compases), transportada a una tercera menor ascendente (mi b mayor - la b mayor).

Con el romántico último tiempo de la Sonata en fa menor de Arregui contrasta considerablemente el tono burlesco y antirromántico del segundo movimiento, Allegro molto scherzando (fa mayor), que anticipa parcialmente algunos procedimientos neoclasicistas como la simplificación del material compositivo y su deformación. Destaca en su forma libre de rondó ( $A_{1}-B_{1}-$ $\left.\mathrm{A}_{2}-\mathrm{C}_{1}-\mathrm{A}_{3}-\mathrm{D}-\mathrm{A}_{4}-\mathrm{C}_{2}-\mathrm{B}_{2}-\mathrm{A}_{5}-\mathrm{Coda}\right)$ la conexión motívica que une los estribillos, variados en cada una de las cinco apariciones, con los episodios a través de derivaciones diastemático-rítmicas.

Sin duda, la pieza más interesante de esta sonata es la primera, Lento y triste a modo de marcha fúnebre (fa menor), no solamente merced a la complejidad estructural de la forma palindrómica $\left(\mathrm{A}_{1} \mathrm{~A}_{2}-\mathrm{B}_{1}-\mathrm{C}_{1} \mathrm{C}_{1}{ }^{\prime}-\mathrm{DD}^{\prime}-\mathrm{C}_{2}-\mathrm{B}_{2}-\mathrm{A}_{1}{ }^{\prime}\right)$ y a la soltura armónica caracterizada por la afuncionalidad, sino sobre todo por ser uno de los ejemplos más tempranos del impresionismo musical en una obra española.

Seguramente no es casualidad que Bacarisse, en su temprana producción de los años 20, influida por el impresionismo francés, se inspirara en un poema del nicaragüense Rubén Darío, cuyo modernismo orientado hacia Francia sería decisivo para la evolución de la poesía española del siglo xx. Además se supone que el compositor conocía la aspiración del poeta, estimulada por su musicalidad, de relacionar la literatura con la música, ${ }^{14}$ como reveló con respecto al poema

12. Collet, Henri. L'essort de la musique espagnole au XXe siècle. París: Max Eschig, 1929, p. 134.

13. Unión Musical Española (Madrid), 1923. Edición agotada. Disponible a través de la Biblioteca Nacional y del Conservatorio Superior de Música de Madrid.

14. La relación del poeta con la música estudió Lorenz, Erika. Rubén Darío - bajo el divino imperio de la música-. Studie zur Bedeutung eines ästhetischen Prinzips. Hamburger romanistische Studien. B. Ibero-amerikanische Reihe, vol. 24. Hamburg: Kommissionsverlag Cram, de Gruyter \& Co, 1956. 
«Heraldos» ${ }^{15}$ donde procura demostrar la «teoría de la melodía interior». ${ }^{16}$ De este poema, en el cual están especificadas algunas figuras femeninas de la mitología con sus respectivos atributos, Bacarisse sustrajo el título - Heraldos - que da nombre a tres piezas de carácter, compuestas en 1922 (op. 2a). Además de la adopción del título y de los nombres de tres personajes del poema - Helena (I), Makheda (II) y Lía (III) — para subtitular los movimientos individuales, está encabezada cada pieza en la primera edición de $1922{ }^{17}$ con una cita de los versos uno, dos y cuatro, ${ }^{18}$ respectivamente, ${ }^{19}$ los cuales hacen pensar en una inspiración extramusical que supuestamente influye en el contenido del ambiente de la composición. Aunque todos los movimientos de Heraldos están caracterizados por criterios estilísticos impresionistas, es el segundo donde se realiza de la manera más contundente el ideal del impresionismo musical a raíz de su configuración versátil y resplandeciente determinada por fragmentos concisos, significativos e instantáneamente activos.

La Sonata fantasía op. 59 de Turina fue compuesta en el «fecundo año $1930 »{ }^{20}$ y publicada dos años más tarde, al igual que las mencionadas obras de Arregui y Bacarisse, por la madrileña editorial Unión Musical Española con una dedicatoria dirigida al musicógrafo José Subirá. El primero de los dos movimientos del op. 59, Lento - Allegro molto moderato, corresponde, aunque en sentido amplio, a la forma sonata que contrasta estructuralmente con el segundo tiempo, Lento, cuyo subtítulo «Coral con variaciones» enmascara una notable complejidad en cuanto a forma y contenido, puesto que el principio de variación está extendido considerablemente al abarcar tanto motivos, frases y fragmentos temáticos como secciones íntegras que no sólo proceden del segundo movimiento sino también del primero, lo cual atribuye a crear, de manera innovadora, la unidad cíclica de la obra, subrayada ya por Iglesias. ${ }^{21}$ Teniendo en cuenta la fecha de creación, 1930, causa sorpresa la multitud de recursos impresionistas, sobre todo en el primer movimiento, no obstante, parecen una constante en las obras de Turina, compuestas a continuación del Quinteto para piano y cuerda op. 1 (1907), ${ }^{22}$ según demuestra el estudio de José María Benavente, quien, quizá extraviado por la convencionalidad del título del Opus 59, lo excluye de sus investigaciones. ${ }^{23}$

15. Contenido en Darío, Rubén. Prosas profanas. Buenos Aires, 1896 y París, 1901.

16. Darío, citado en Lorenz, op. cit., p. 79.

17. Unión Musical Española (Madrid), 1922.

18. El último verso está acortado.

19. Op. $2 a, n^{\circ} 1$ : ¡Helena! La anuncia el blancor de un cisne. Op. 2a, $n^{\circ} 2$ : ¡Makheda! La anuncia un pavo real. Op. 2a, $\mathrm{n}^{\circ}$ 3: ¡Lía! Anúnciala un paje con un lirio.

20. Iglesias, Antonio. «Sonata-Fantasía.» Joaquín Turina (su obra para piano), vol. 2. Madrid: Alpuerto, 1990, p. 325.

21. Ibid, p. 326.

22. Según Turina, la opinión de Isaac Albéniz fue decisiva para que cambiase su estilo de composición. Turina, Joaquín. «Encuentro en París con Isaac Albéniz [1941/43].» Escritos de Joaquín Turina. Recopilación y comentarios Antonio Iglesias. Madrid: Alpuerto, 1982, p. 207.

23. Bena VEnte, José María. «Cap. IV. El impresionismo musical y Turina.» Aproximación al lenguaje musical de J. Turina. Madrid: Alpuerto, 1983, pp. 139-172. 
2. Criterios estilísticos del impresionismo musical y su aplicación por Arregui, Bacarisse y Turina

A continuación se exponen los principales medios de composición del impresionismo musical al tiempo que se estudia su empleo en las mencionadas obras para piano de Arregui, Bacarisse y Turina.

\subsection{Tratamiento sonoro}

Una característica primordial de la técnica de composición impresionista es la preponderancia de estructuras homófonas basadas en sucesiones sonoras afuncionales. Respecto al acoplamiento de sonidos llama la atención la tendencia de yuxtaponer sonidos análogos o similares, siendo desatendida la funcionalidad armónica entre ellos, con lo cual se producen las llamadas «mixturas» que son, según Hans Albrecht, el medio estilístico armónico «más popular» del impresionismo. ${ }^{24}$ Correspondiente a la configuración de su estructura sonora, rígida o variable, respectivamente, se distinguen mixturas estrictas y mixturas tanto libres como tonales o modales.

Efectivamente, en las tres composiciones en cuestión este importante medio estilístico aparece en la primera sección formal, y es interesante observar la función que tiene en cada una de estas obras. Arregui lo empleó tras haber expuesto tres veces el motivo principal formado de un tetracordo frigio descendente, que al final de la tercera aparición prescinde del anterior giro semicadencial, insistiendo en su lugar el bajo durante varios compases (cc. 11-15) en el intervalo concluyente de semitono antes de retomar la voz superior una variante rítmica del motivo principal (c. 16). Es precisamente en este estático pasaje transitorio de pedal de Dominante (tono fundamental alternado con su sensible superior), donde Arregui utilizó en la mano derecha por primera vez en la sonata acordes paralelos de séptima que al progresar inicialmente por terceras ascendentes, parecen cumplir sólo un cometido colorístico, sin embargo adoptan a partir del compás 14 una función cadencial en relación con la tríada final (c. 16), Tónica de la tonalidad principal (fa menor), al pasar por la doble Dominante (con quinta disminuida y séptima) y la Dominante (con sexta menor y séptima) de ésta, anticipándose su tercera a consecuencia de la modificación en la estructura de la mixtura en el penúltimo acorde (c. 15: quinta $\rightarrow$ sexta menor).

24. Albrecht, Hans. «Impressionismus.» Die Musik in Geschichte und Gegenwart (MGG), vol. 6. Coord. Friedrich Blume. Kassel: Bärenreiter, 1957 (DTV, 1989), columna 1070. 


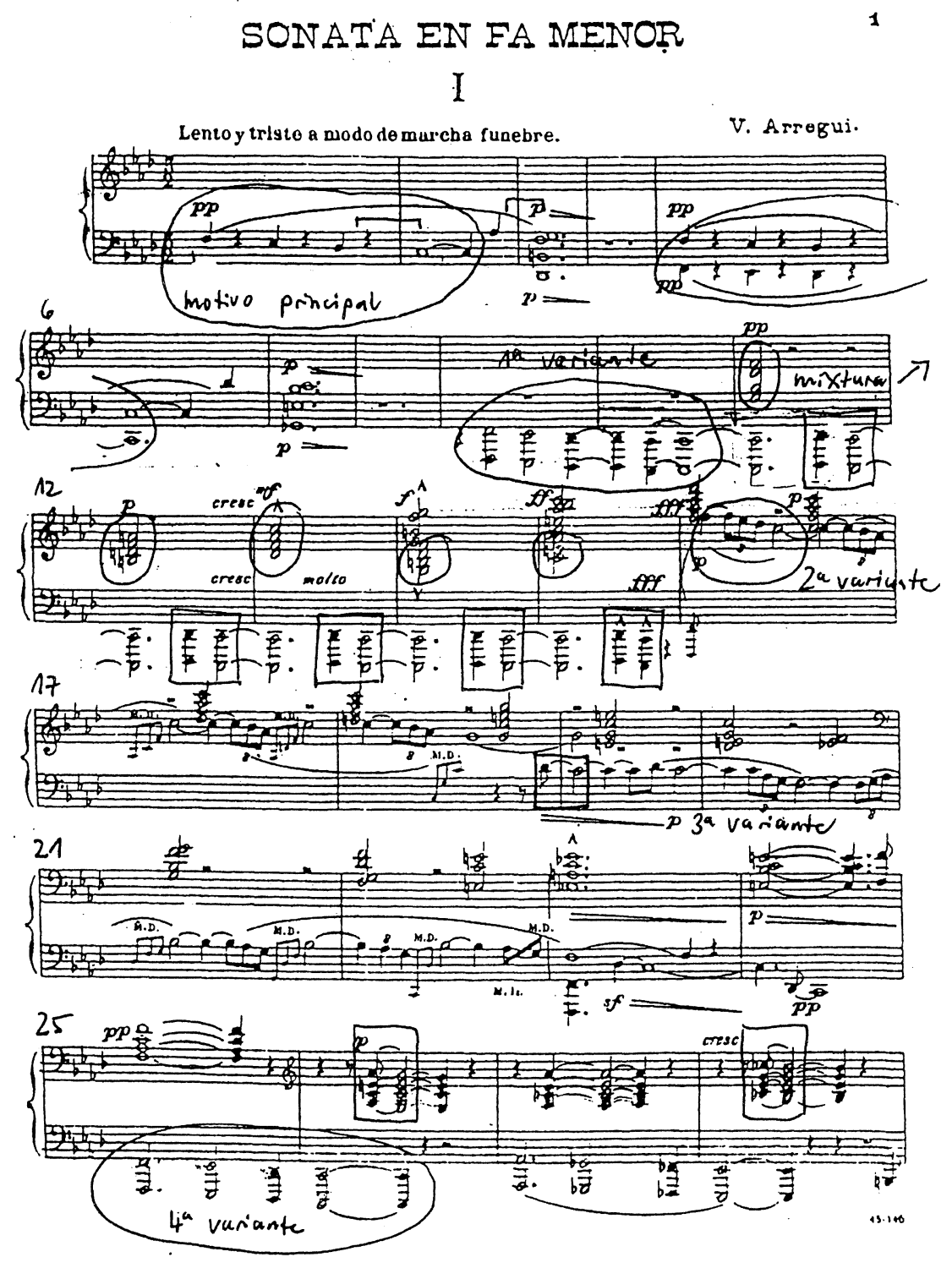

Ejemplo 1: Arregui, Sonata en fa menor I, cc. 1-16

Al contrario de Arregui, tanto Bacarisse en la primera pieza de Heraldos como Turina en el primer movimiento de la Sonata fantasía, utilizan mixturas para crear una peculiar sonoridad en la sección inicial además de poner de relieve la melodía principal o, en el caso de Turina, su respectivo contrapunto. El Lento que constituye la introducción de la sonata de Turina está caracterizado por la sonoridad de quintas vacías llevadas paralelamente por la mano izquierda, la cual 
alterna el rítmico contrapunto derivado del motivo inicial de la mano derecha (cc. 1-2) con acordes de reposo (c. 3), aprovechados éstos por la mano derecha para invertir, tras exponer el motivo inicial, una ampliación interválica (cc. 3-4) de este contrapunto con la novedad de reforzar melódicamente la voz inferior a través de una mixtura de quinta y octava.

\section{SONATA FANTASIA}
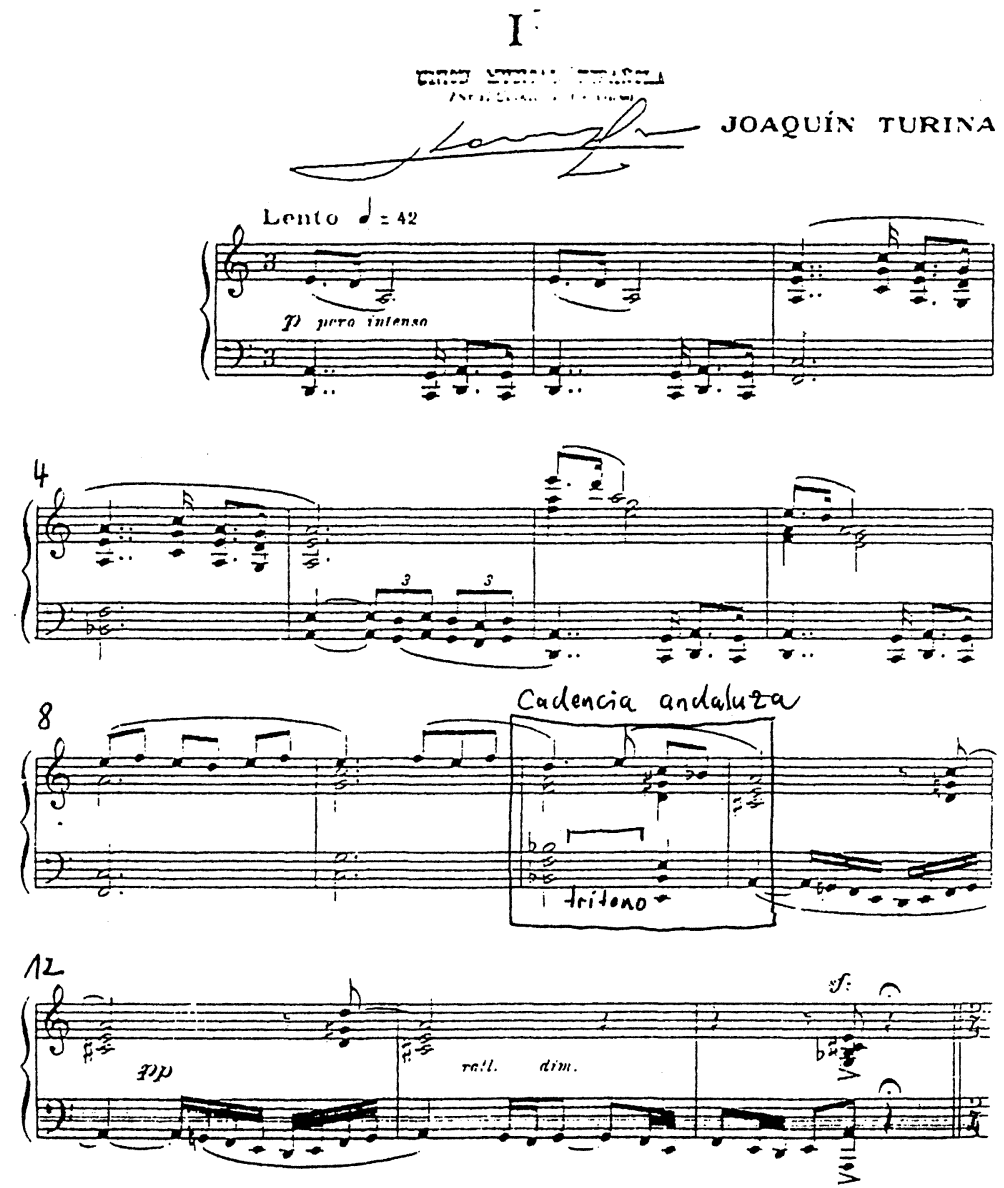

Ejemplo 2: Turina, Sonata fantasía I, cc. 1-11

Frente al permanente diálogo entre ambas manos que junto a la sonoridad de quinta caracteriza esta sección introductoria de la sonata de Turina, la textura de la primera parte formal de Helena, donde Bacarisse optó por la sonoridad de cuartas estratificadas, es mucho más estática debido a la monotonía de reiterados acordes de segunda en la mano izquierda, que acompaña las mixturas de cuarta y séptima de la mano derecha, cuyo desplazamiento horizontal produce la patética melodía. 


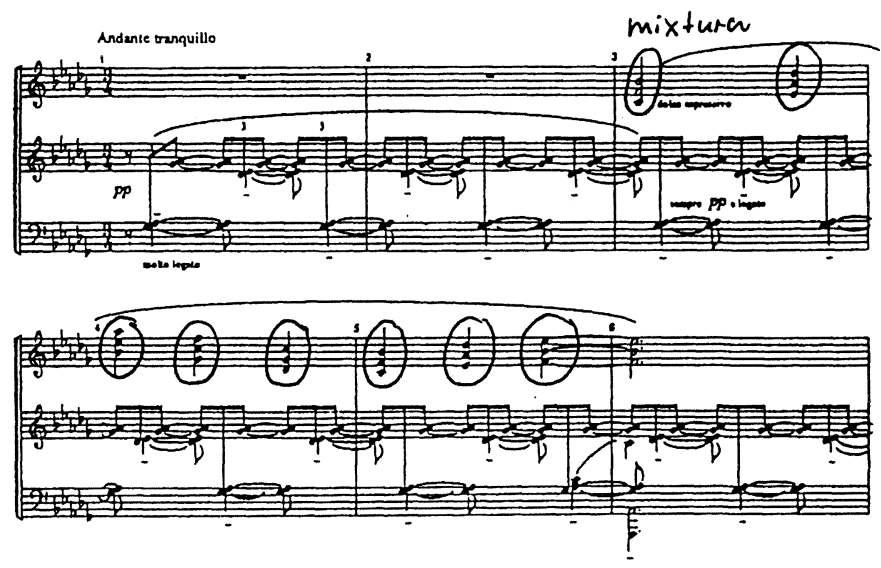

Ejemplo 3: Bacarisse, Heraldos I, cc. 1-6

Otra técnica impresionista para acoplar dos o más acordes, aunque menos frecuente que el empleo de mixturas, es la progresión cromática conducida en sentido contrario por algunas voces o paralelamente por todas las voces que de esta manera ocasionan una forma particular de la técnica de mixtura. Progresiones cromáticas para enlazar distintos sonidos horizontalmente en más de una voz están poco usadas por Arregui en la Sonata en fa menor, si bien en ésta el cromatismo es melódicamente abundante, sobre todo como giro conclusivo en sentido descendente. A semejanza de la utilización de mixturas, Arregui empleó la progresión cromática también en un pasaje transitorio de dos compases (cc. 36-37) que tiene una función modulatoria al conducir de la b mayor a una tríada de do \# mayor que a su vez hace de Dominante de la siguiente sección formal que entra en el compás 38 (fa $\sharp$ menor).

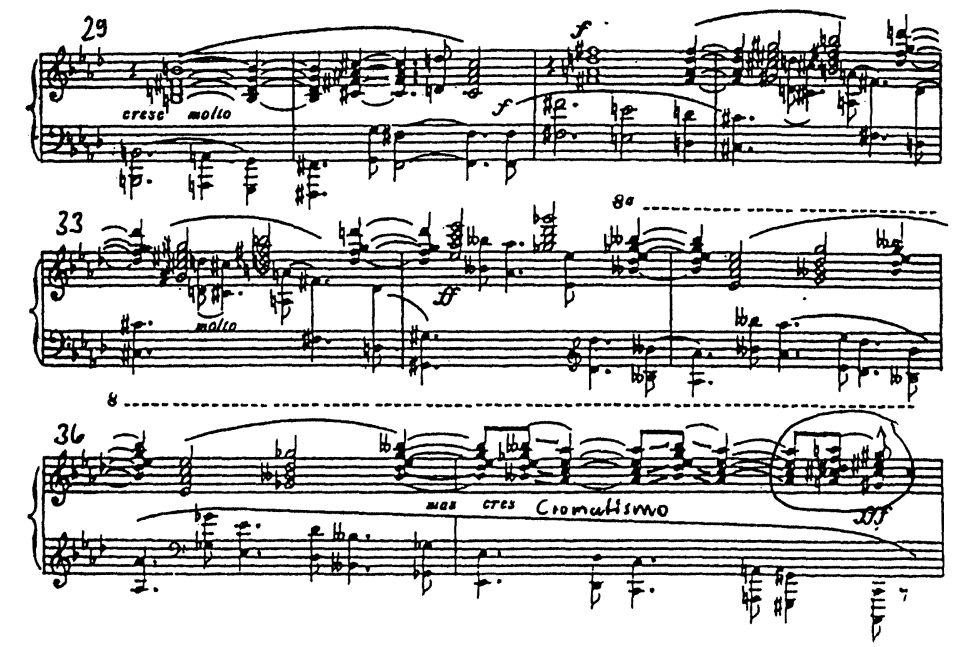

Ejemplo 4: Arregui, Sonata en fa menor I, cc. 36-37 
Un ejemplo sublime de progresión cromática en ambos sentidos se halla en el acompañamiento del comienzo de la segunda pieza de Heraldos de Bacarisse, donde, excepto el primer intervalo de la voz superior, tres acordes están enlazados a través de semitonos. Tanto la disolución rítmica como las reiteraciones de cada uno de estos acordes motivan un enmascaramiento de esta estructura sonora que se erige sobre un pedal de duodécima y doble octava (La"mi-la).
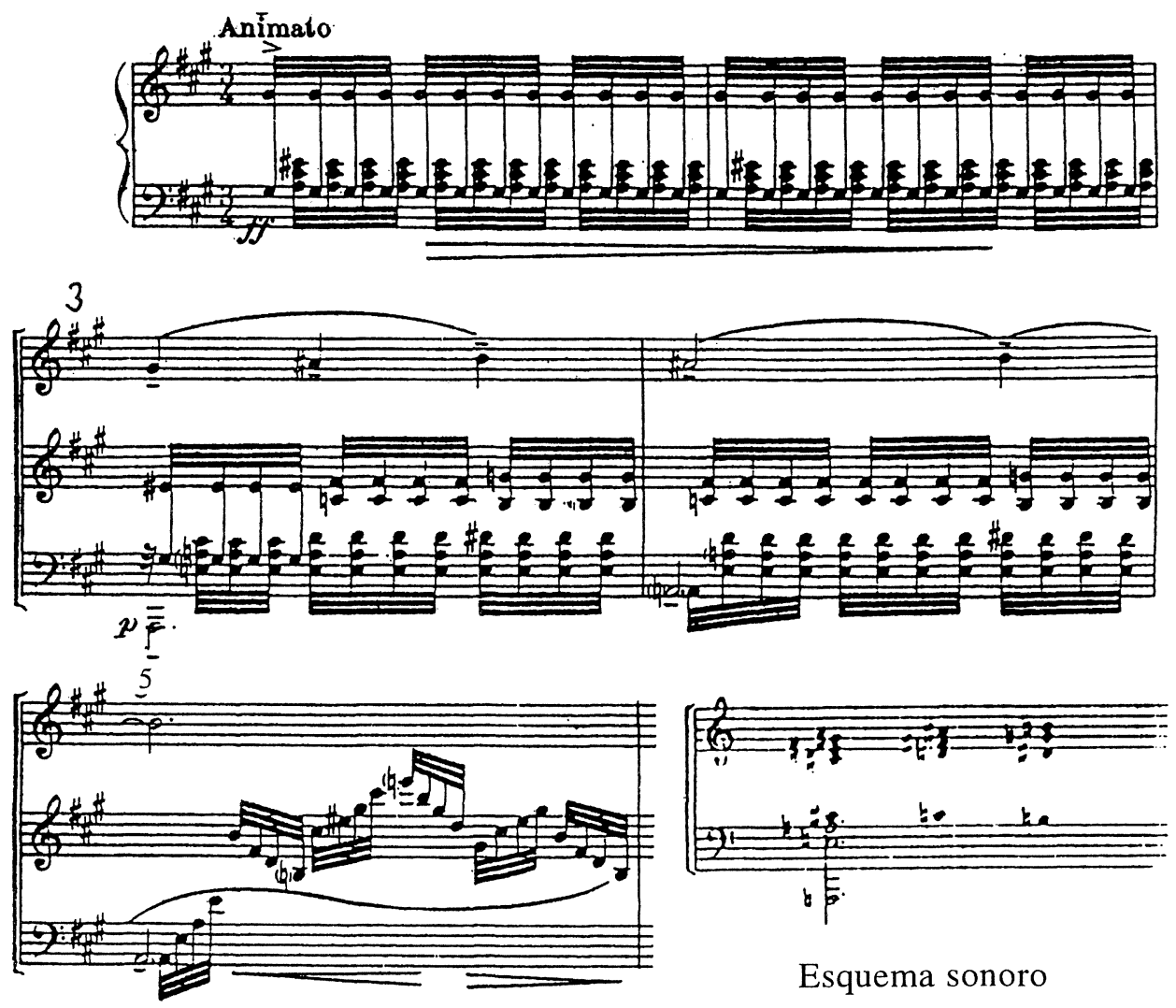

Esquema sonoro

Ejemplo 5: Bacarisse, Heraldos II, cc. 1-5

En su temprana época estilística utilizó Bacarisse unas series cromáticas a muchas voces principalmente para conectar dos secciones formales contrastantes, como es el caso del tránsito hacia el clímax de Makheda, donde el rápido ascenso cromático de una mixtura de tríadas en segunda inversión, cuya base (cuartas paralelas) está alternadamente anticipada por la mano izquierda, provoca un incremento de la tensión, reforzado por medios dinámicos. 

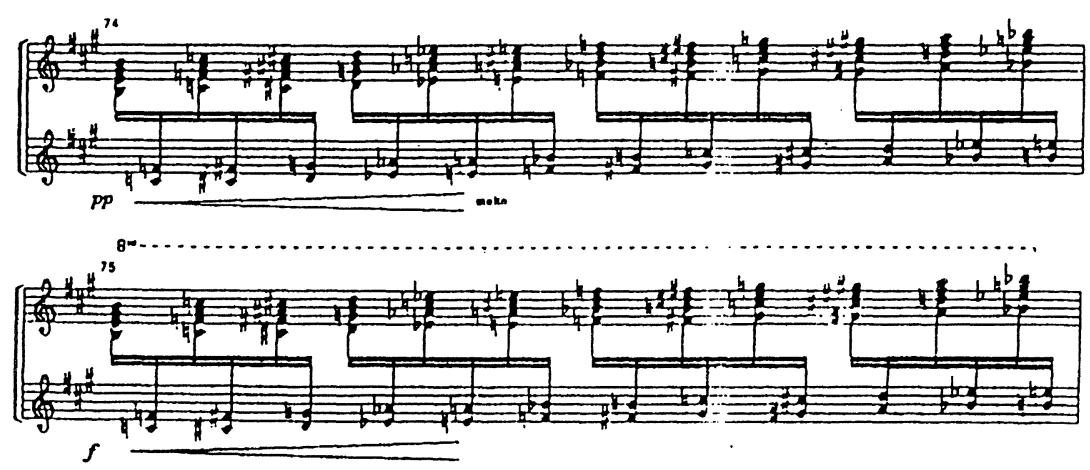

Ejemplo 6: Bacarisse, Heraldos II, cc. 74-75

En la Sonata fantasía de Turina, el acoplamiento cromático en más de una voz tampoco es frecuente, no obstante, al final del primer movimiento hay un procedimiento combinatorio de mixturas y progresiones cromáticas muy similar al de Bacarisse en Makheda. Pero en vez de limitarse como éste a una función meramente conectiva, Turina, al abrir la Coda (cc. 191 ss.), emprende una retrospectiva motívica hacia la introducción, multiplicando el motivo inicial verticalmente a través de una mixtura de cuarta o quinta y octava (mano derecha), la que se reúne con los acordes paralelos de segunda y cuarta aumentada del acompañamiento (mano izquierda) en sonidos a cinco voces que ascienden cromáticamente sin tener nexo armónico-funcional alguno (cc. 191-196), hasta quebrarse en el segundo tiempo del compás 195 al conducir hacia el último clímax que desemboca en una tríada de re mayor, Tónica de la tonalidad principal con la cual concluirá éste tiempo.

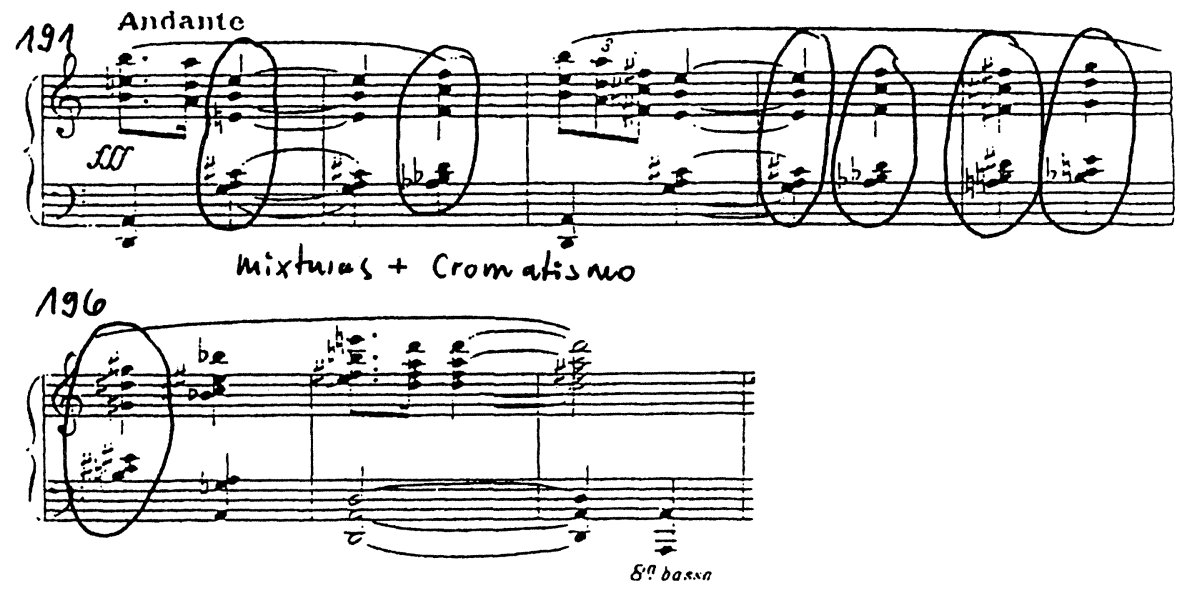

Ejemplo 7: Turina, Sonata fantasía I, cc. 191-198 
Otro de los criterios estilísticos predominantes de la música impresionista en lo que al tratamiento sonoro se refiere es la estratificación de intervalos cualquiera, sobre todo de terceras, pero también de cuartas y quintas, con las respectivas inversiones. En las tres obras analizadas hay abundantes ejemplos de estratificaciones sonoras, empleadas sobre todo por Arregui y Turina para subrayar el tránsito hacia nuevas partes formales, además de incrementar la tensión sonora en determinados lugares de particular interés musical.

Arregui utilizó preferentemente estratificaciones de terceras, comprobado ya con motivo del empleo de mixturas de acordes de séptima al comienzo de la obra (véase ejemplo 1), pero también son frecuentes configuraciones invertidas que producen colocaciones de segundas (véase ejemplo 4). Resalta que los sonidos más complejos en el primer movimiento de la Sonata en fa menor no cuentan más de cinco notas, a las que hay que añadir eventuales sonidos restantes pertenecientes a la estructura melódica. Es paradigmática la binaria parte central del mismo tiempo, donde, al final de cada una de las dos subsecciones, el procedimiento de secuenciación de una diminuta fórmula semicadencial en la voz superior (cc. 59-61 y 67-69) contrasta con el descenso parcialmente cromático de una mixtura de acordes paralelos de séptima disminuida $\left(\mathrm{D}^{\vee}\right)$ que transcurre sobre un pedal del tono fundamental de la Dominante de la respectiva parte formal (fa mayor / mib mayor).

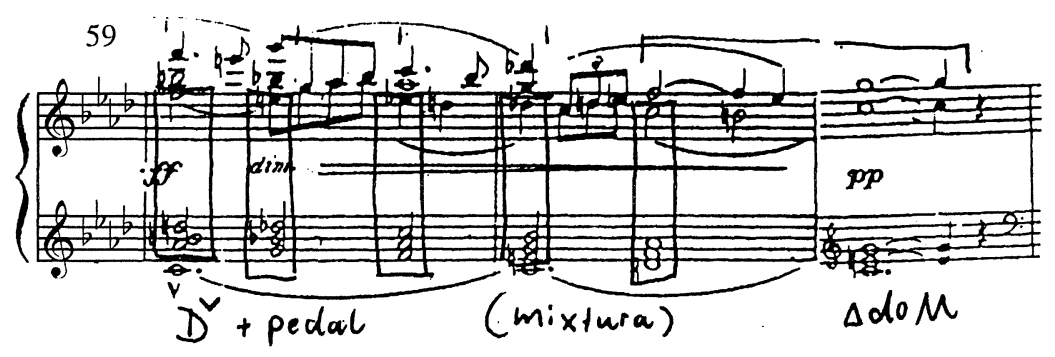

Ejemplo 8: Arregui, Sonata en fa menor I, cc. 59-61

También en la sonata de Turina, las estratificaciones sonoras se encuentran en pasajes formalmente decisivos, y son raras las veces en las que la densidad sonora es mayor a cuatro voces, como se ha podido comprobar en la Coda del primer movimiento (véase ejemplo 7). La periódica sección formal que prepara la entrada de la parte de desarrollo, Poco meno (cc. 79-86), se sirve de estratificaciones de terceras para aumentar la expectativa referente a la sección siguiente, al concluir cada semiperíodo con un sonido a seis voces que significa el máximo de densidad sonora en el movimiento entero. La configuración acordal de este pasaje, que parte de una estratificación de tres intervalos de tercera (lab-do-mi b-sol), es al mismo tiempo paradigmática en cuanto al procedimiento de fraccionamiento sonoro, puesto que en realidad se compenetran por medio de dos acordes análogos dos diferentes regiones sonoras basadas en lab mayor y do menor, respectivamente, cuya independencia se ve reforzada por la función melódica del acorde superior que recuerda, de manera modificada, a través de la ritmización el contrapunto de la introducción (cc. 79-80). 


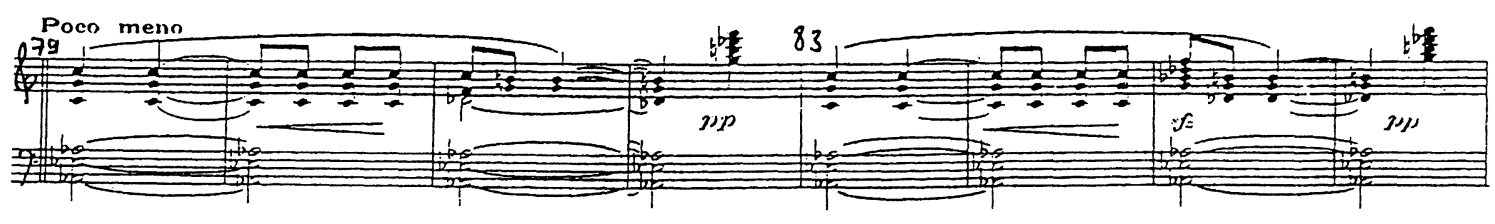

Ejemplo 9: Turina, Sonata fantasía I, cc. 79-86

Frente al empleo moderado y funcional de las estratificaciones sonoras en las correspondientes composiciones de Arregui y Turina, el uso que Bacarisse hizo de ellas en las dos primeras piezas de Heraldos es bien diferente por primar sobre las respectivas secciones iniciales la acumulación de terceras (en Makheda, véase ejemplo 5) y cuartas (en Helena, véase ejemplo 3). En Helena llama la atención que con la entrada de la mano derecha en el compás 3 se produce ya un sonido a siete voces - el mismo que concluirá la pieza-, procedentes del círculo de cuartas ( $\mathrm{sol} b \rightarrow \mathrm{do}$ ), cuyo tratamiento instrumental, sin embargo, atribuye a mitigar el efecto disonante a causa del fraccionamiento sonoro con medios rítmicos, dinámicos y agógicos, separándose con ello el campo melódico del estático ambiente del acompañamiento. La ausencia de funcionalidad de las estratificaciones sonoras en estas piezas — presente también en otras obras impresionistas de Bacarisse, sobre todo para gran orquesta ${ }^{25}$ - se debe al concepto de contraste y yuxtaposición motivado a su vez por el intencionado carácter que se deduce del correspondiente modelo literario.

Por lo general, la música impresionista no renuncia a ligazones tonales, a pesar $-\mathrm{o}$ a raíz- de la yuxtaposición de acordes afuncionales, lo que se manifiesta en la manutención de rudimentos procedentes de la tradicional funcionalidad armónica, como son la indicación de las armaduras además del enlace de distintas partes formales a través de un parentesco de quinta, comprobable en las tres composiciones analizadas.

Por lo expuesto hasta ahora debe sorprender que junto a Arregui también Bacarisse siguió aferrado a la determinación tonal mediante armaduras (Helena: re b mayor; Makheda: la mayor), al contrario de Turina que prescindía de ello, aunque la imagen sonora en su sonata, basada en quintas vacías y tríadas, esté mucho más modesta que la de los dos primeros movimientos de Heraldos.

Un papel importante en la música impresionista, primordialmente en casos de combinaciones sonoras funcionalmente inexplicables, tienen los efectos organales producidos mediante la técnica de bordón y la técnica del sonido central. En Arregui se observa la tendencia de combinar las mixturas, sobre todo de acordes de séptima, con un pedal de bajo que cumple la función de bordón al ser el punto de referencia tonal de los respectivos fragmentos (véase ejemplo 1, cc. 11-15, y ejemplo 8, cc. 59-60). La importancia que Arregui prestó al bordón como sostén armónico se afirma en la Coda del primer movimiento de la Sonata en fa menor, donde el pedal de «fa» (cc. 100 ss.) anuncia la futura entrada de la Tónica, demorada por el proceso de secuen-

25. Véase Heine, op. cit., pp. 105-107. 
ciación - muy frecuente en esta obra- de una configuración melódica descendente en unísono, último recuerdo al transformado motivo principal, y su respectivo acorde final de séptima no resuelto.

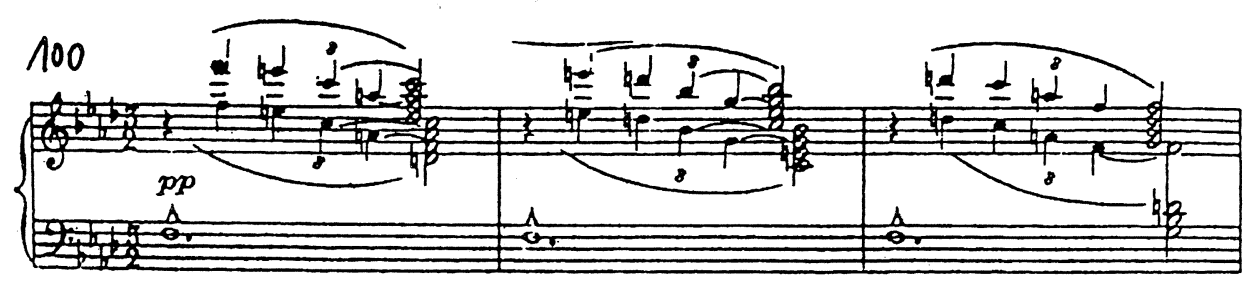

Ejemplo 10: Arregui, Sonata en fa menor I, cc. 100-102

La unión entre bordón y mixtura también está presente en Heraldos, aunque de manera más compleja que en la sonata de Arregui: En el tránsito hacia la recapitulación del tercer movimiento, Lía, se superponen a distancia de un tritono un estático campo sonoro consonante (mano izquierda), formado de una tríada de si b mayor, y una mixtura de cuarta y octava (mano derecha) cuyo desplazamiento horizontal da lugar a los primeros dos compases del tema (cc. 27-28). El efecto bitonal, consecuencia de la conjunción de dos diferentes campos tonales, produce una eminente tensión, resuelta sólo con la entrada de la nueva parte formal (c. 29), cuando la fundamental y la quinta del campo estático pasan en forma de sensibles «napolitanas» a las correspondientes notas de la tríada de la menor.

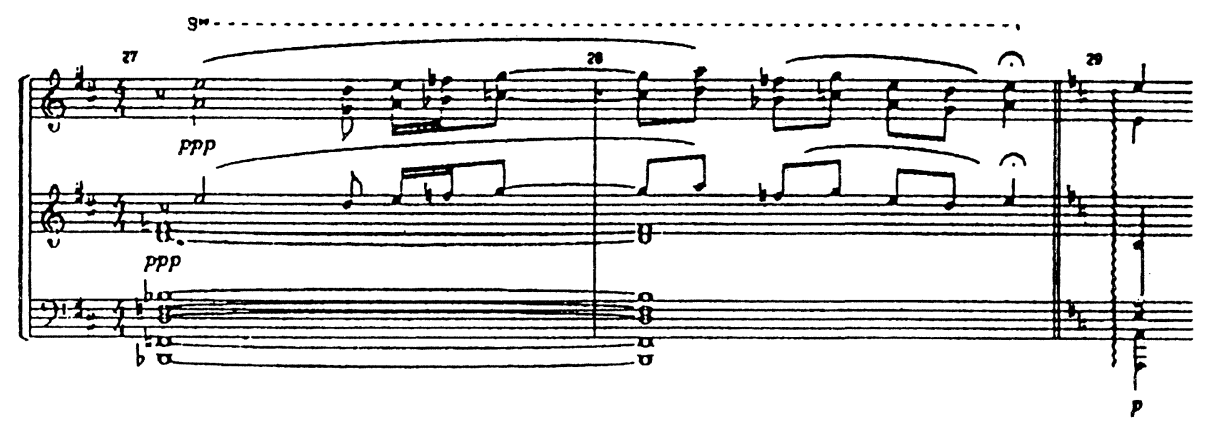

Ejemplo 11: Bacarisse, Heraldos III, cc. 27-29

En la sonata de Turina el empleo del bordón, confiado a la voz media, está estrechamente relacionado con la primera sección de la exposición (cc. 15 ss.), extendiéndose su cometido, más allá de sostener la tonalidad, a crear, en conjunto con el ostinato del bajo, una cierta imagen sonora arcaica basada en quintas vacías, la que arropa la flexible voz superior, cuya ceñida melodía, derivada del contrapunto de la introducción, tiene parentesco tanto diastemático como rítmico con el anterior ejemplo de Bacarisse (véase ejemplo 11). 


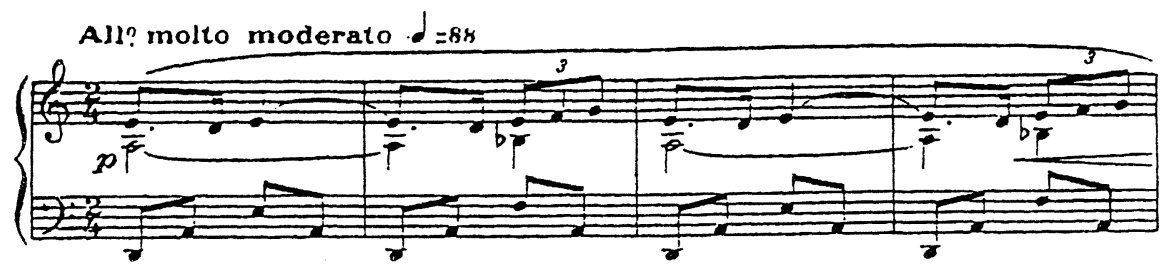

Ejemplo 12: Turina, Sonata fantasía I, cc. 15-18

Donde a raíz de la situación sonora no se dejan verificar ningunas relaciones armónicamente funcionales, como en el caso de acordes simétricos, algunos compositores impresionistas, entre ellos Bacarisse, introducían notas de pedal que actúan momentáneamente de centros tonales. Consta que las sonatas de Arregui y Turina no precisan la aplicación de centros tonales a causa de su tratamiento armónico, distinguido principalmente por el abundante empleo de tríadas, parentescos de quinta o tercera y procedimientos cadenciales. A diferencia de ellos, la complejidad sonora de las dos primeras piezas de Heraldos requiere recursos que, sobre todo en lugares formalmente determinantes, recuerdan la ligazón tonal, puesta de manifiesto a través de las correspondientes armaduras.

De las múltiples muestras existentes en Heraldos sirve de ejemplo la bitonal Coda de Makheda (cc. 99-103) que resume los ocho primeros compases de este movimiento. En ésta, un sonido central cumple una función cadencial, insinuando las repetidas alternancias del intervalo de quinta (Mi-La') en el bajo las relaciones armónico-funcionales asociadas con la «Dominante» y la «Tónica» de la tonalidad indicada (la mayor). La insistencia en este sonido central está motivada por su divergencia del centro tonal ( $\mathrm{fa} \#$ ) en que se basa la armonización de la melodía, conducida en una mixtura de tríadas paralelas hacia el final de la pieza, donde se fundan ambos campos sonoros en un acorde disonante a cuatro voces (tríada aumentada con séptima mayor).

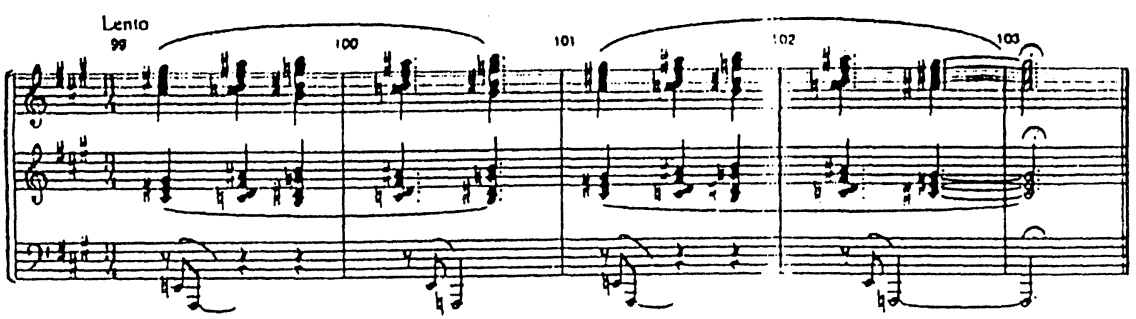

Ejemplo 13: Bacarisse, Heraldos II, cc. 99-103 
La saturación del cromatismo motivó en algunos compositores impresionistas la recurrencia a sonoridades arcaicas, sirviéndose de la armonía modal, la cual fue «modernizada» a través de su combinación con técnicas compositivas propias del temprano siglo xx.

Si exceptuamos la modalidad del motivo inicial de la Sonata en fa menor, inspirada en la cadencia frigia o tetracordo andaluz, la armonía modal, al igual que la técnica del sonido central, no se adentró en la sonata de Arregui, quien, pese a la abundancia de configuraciones sonoras armónicamente afuncionales, solía enlazar dos diferentes secciones estructurales a través de notorias fórmulas cadenciales $\left(D^{7}-t\right)$ además de los habituales parentescos de quinta, lo cual pone de manifiesto su profundo arraigo en la tradición armónica de la época clásicoromántica.

Bacarisse, por su parte, aplicó la armonía modal sólo al final de su producción impresionista, precisamente en la tercera pieza de Heraldos, cuya armonización efectúa cadencias modales, caracterizadas por evitar premeditadamente cualquier efecto de sensible al utilizar la Dominante menor. La armonización del antecedente melódico (cc. 1-2) que acaba en semicadencia (I-IV-V) estriba en la escala frigia (sobre «la») y modula en el consecuente (cc. 3-6) a la tonalidad de la Subdominante (re menor), confirmada de forma tradicional con una cadencia del cuarto y quinto grado menores (ambos con séptima y novena menor). Este tratamiento arcaico del acompañamiento homófono obtiene un matiz moderno merced a la individualización del bajo fundamental de las demás voces que transcurren en gran parte paralelamente en mixturas de cuarta y sexta, produciéndose con ello abundantes quintas paralelas además de falsas relaciones entre las distintas partes.
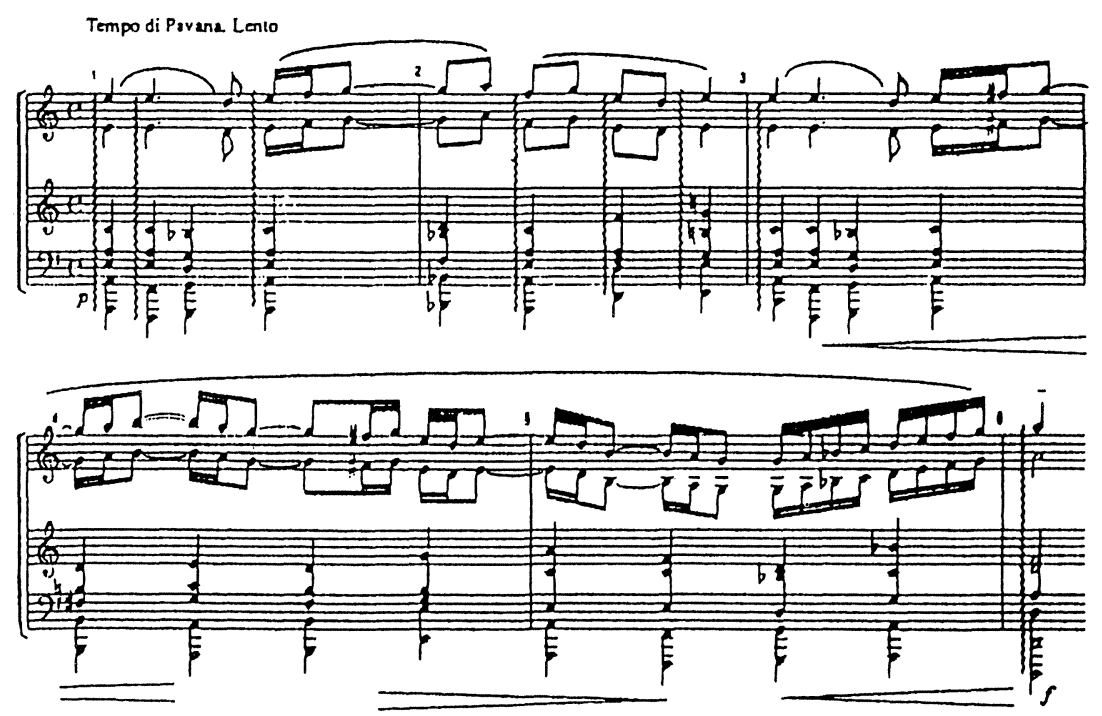

Ejemplo 14: Bacarisse, Heraldos III, cc. 1-6 
En Turina, la modalidad es un rasgo característico de su estilo impresionista, según comprobó Benavente en gran número de las composiciones de éste, ${ }^{26}$ y también es perceptible en la Sonata fantasía, cuyo material sonoro se funda, al igual que Lía de Bacarisse, parcialmente en el modo frigio sobre «la» (véase ejemplo 2, cc. 1-11). Merece especial atención el tratamiento de la cadencia andaluza, constante persistente en la obra de Turina, quien la variaba según sus menesteres sonoros de manera muy particular. ${ }^{27}$ La sección introductoria de la sonata op. 59 concluye con una versión cadencial en la cual se solapan los acordes del alterado tercero y acortado segundo grado, ${ }^{28}$ manteniéndose en el bajo la estructura de quinta paralela, determinante en esta sección, cuyo desplazamiento horizontal produce en ambas voces un llamativo salto de quinta disminuida (véase ejemplo 2, cc. 10-11).

\subsection{Tratamiento melódico}

La estructura melódica de la música impresionista desempeña, por lo general, un papel subordinado al tratamiento armónico, haciéndose patente en Helena de Bacarisse, donde la melodía es producto del desplazamiento horizontal de las mixturas (véase ejemplo 3). Con mucha frecuencia las melodías impresionistas se pronuncian en escuetos motivos, los que en algunos casos o sustituyen un tema hábil o forman melodías lacónicas a través de procedimientos tradicionales como la repetición, aumentación, disminución, inversión y otras modificaciones de índole tanto diastemático como rítmico. A veces, un solo motivo proporciona el material compositivo de una o varias secciones íntegras, como es el caso del primer movimiento de la Sonata en fa menor. Arregui parte de una diminuta configuración interválica de tres segundas descendentes concluida con un semitono (segundo tetracordo - frigio- de la escala menor natural), el cual, al ser apartado del motivo principal, consigue un singular interés de célula individual, por aprovecharse su carácter conclusivo para fines afirmativos, como en la exposición del motivo inicial (cc. 17), o para cumplir un cometido de reposo, como en el fragmento transitorio hacia la modificación de este motivo (véase ejemplo 1, cc. 11-15). Excepto la parte central (cc. 54-69) donde además de una escala frigia se presenta como material compositivo nuevo una célula ondulante de quinta descompuesta, todas las demás secciones de la forma palindrómica de este primer tiempo se remontan melódicamente al motivo inicial, diferenciándose sin embargo en cuanto al tratamiento que reciben y que abarca todos los parámetros.

Ya en la primera parte formal (cc. 1-24) el motivo principal, que progresa originariamente con un ritmo uniforme de blancas «cortadas» y reposa sobre la parte fuerte del siguiente compás, se muestra en tres nuevas variantes, incluida la dislocación rítmica en la sincopada tercera presentación (cc. 9-11). Las modificaciones de la segunda variante (cc. 16-18), que abre un nuevo fragmento formal, abarcan el ritmo (disminuido con tresillo), el registro (agudo en vez de grave), la dinámica (piano en vez de pianísimo) y la función de este motivo que se convierte en un ele-

26. Benavente, «4. Lo modal andaluz en el impresionismo de Turina». Op. cit., pp. 150-172.

27. Véase tablas en ibid., pp. 155-158.

28. Es una variante del ejemplo ${ }^{\circ}$ XIII en ibid., pp. 156 y 162. 
mento figurativo a la vez de conjuntivo que, al desprender de la fundamental de la Tónica de la tonalidad principal, acopla los acordes de una progresión armónica descendente (véase ejemplo 1, cc. 16-18). Ésta continúa hasta llegar a un acorde de Dominante con séptima (c. 24) en combinación con otra variante del motivo inicial, que, manteniendo el tresillo de la versión anterior, reposa sobre alguna nota y extiende, tras insistir en el característico semitono, su acopio sonoro por el primer tetracordo de la escala menor ( $\mathrm{si} b \rightarrow$ fa; véase ejemplo 1, cc. 19-24).

En la segunda sección modulatoria (cc. 25-37) una variante rítmica con puntillo y síncopa del motivo inicial es objeto de un proceso de secuenciación, en el cual además toma parte la célula semitonal al imitar, en forma de nota de retardo de una tríada (sexta $\rightarrow$ quinta), el intervalo conclusivo de aquella a distancia de quinta superior (véase ejemplo 1, cc. 25-28).

El carácter de la siguiente sección (cc. 38-43), clímax del primer movimiento, se diferencia considerablemente de las precedentes por ser la más agitada de todas a la vez que la más cantábile, a consecuencia del acompañamiento figurativo en ritmo de fusas y de la ampliación del motivo principal, recordado sobre todo en la repetida primera frase (cc. 38/39) a través de los intervalos característicos de segunda mayor y menor descendentes. La expresiva melodía que, pese al vigor dinámico $(f f f)$, requiere sensibilidad en la interpretación («con alma»), es tripartita y se compone de diminutas células de dos o tres notas contiguas que son anacrúsicas (con la excepción del comienzo de la primera y la última frase, cc. 38 y 43) y descendentes en las partes extremas, cuyo marcado ritmo yámbico contrasta con la uniformidad de los tresillos en la parte central (cc. 41-42) donde una variante circular de la anterior célula está secuenciada en sentido descendente.

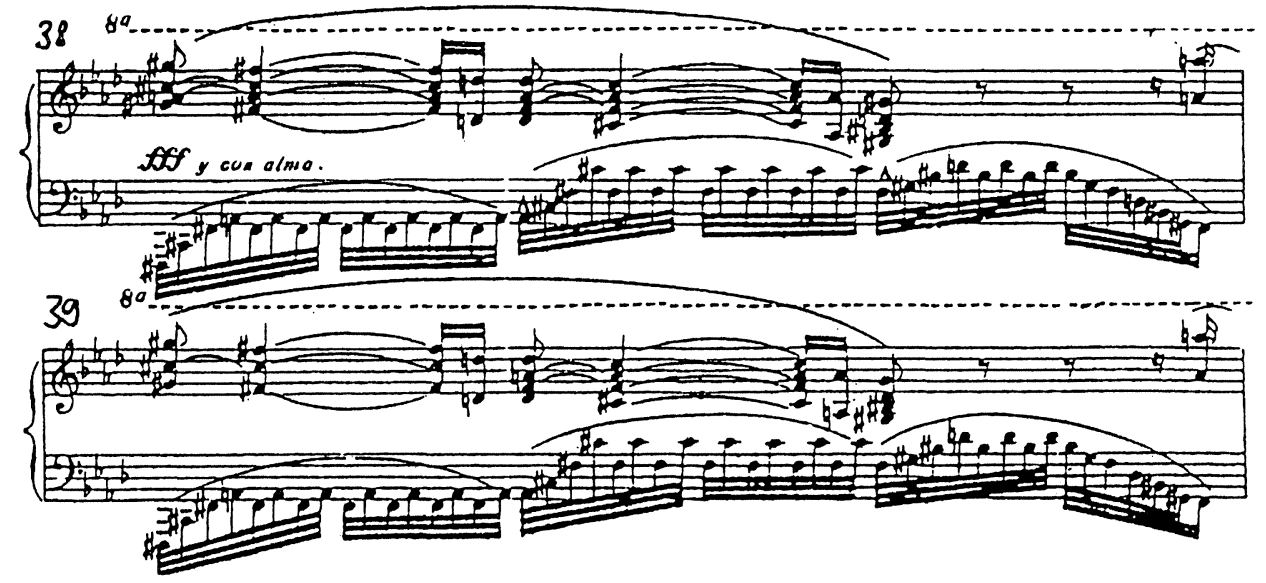

Ejemplo 15: Arregui, Sonata en fa menor I, cc. 38-39

El centro tonal ( $\mathrm{fa} \sharp$ ) de esta homófona sección con acompañamiento arpegiado está enlazado a través de parentesco de quinta con el centro tonal (do\#) de la siguiente sección bipartita 
(cc. 44-53), que reanuda sobre un pedal de Dominante (fundamental) el motivo principal en una disminuida variante rítmica con reposo sobre distintas tríadas, la cual a continuación está secuenciada (cc. 44-47) y reiterada (cc. 48-53).

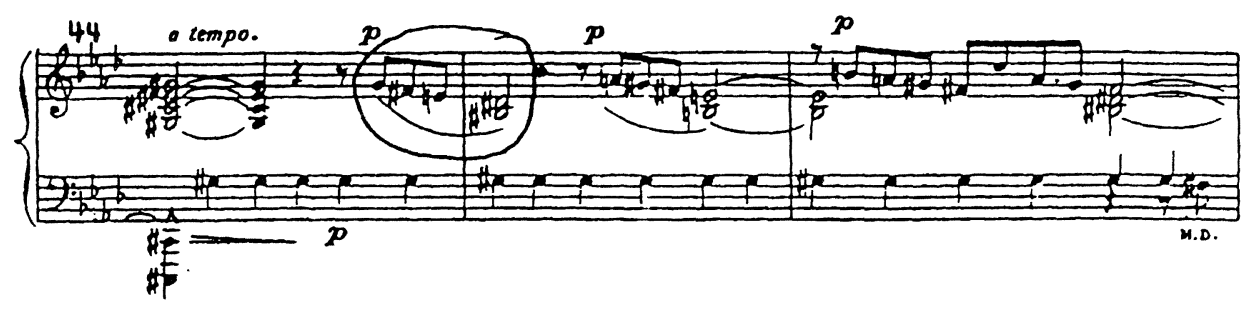

Ejemplo 16: Arregui, Sonata en fa menor I, cc. 44-46

A pesar de la continua transformación a que está sometido en el primer movimiento de la Sonata en fa menor de Arregui un sólo motivo, la célula diastemática originaria del tetracordo frigio descendente queda siempre reconocible gracias a la insistencia en los dos intervalos esenciales de segunda mayor y menor.

También en Makheda de Bacarisse la sustancia melódica de la primera sección (cc. 3-12) es muy escasa, al ser restringida a una tercera menor descompuesta que se prolonga en el último compás a un tetracordo ascendente (c. 12). Pero si Arregui partía deliberadamente de la estructura horizontal a través de una célula diastemática que al ser presentada prescinde del acompañamiento, en Makheda el proceso compositivo es inverso, puesto que el punto de arranque es la estructura vertical sobre la cual se desenvuelve la sencilla melodía bipartita que está estrechamente ligada a la armonía (véase ejemplo 5). Tanto la periodicidad de su estructura (dos períodos con antecedente y consecuente de $3+3$ y $2+2$ compases) como el diatonismo de su material sonoro son vestigios de la tradición clásico-romántica, enmascarados a través de la agria armonización afuncional.

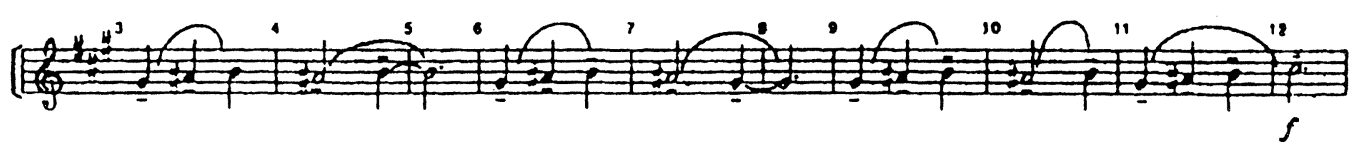

Ejemplo 17: Bacarisse, Heraldos II, c. 3-12

Las repetidas recapitulaciones de esta simple melodía, separadas por varios episodios contrastantes que suscitan algunos de los rasgos más significativos de ésta, son determinantes en cuanto a la estructura formal que se deja interpretar como rondó libre. El tercer episodio (cc. 6375) da muestra de los recursos aplicados por Bacarisse con el fin de conseguir un cambio total de carácter al convertir la naturaleza solemne del estribillo en un jocoso scherzando, cuyo tono bur- 
lesco es consecuencia de múltiples transformaciones de índole diastemática (tercera mayor en vez de menor; ampliación), métrica (compás binario en vez de ternario), rítmica (ritmo saltadizo de puntillo en vez de ritmo uniforme), agógica (corcheas en vez de negras; tempo «vivo»), expresiva (staccato) y contrapuntística (figuraciones circulares con tresillos en contratiempo).

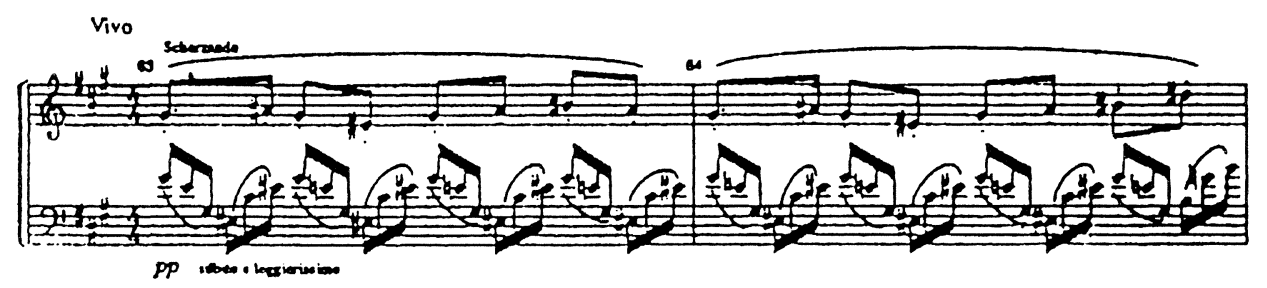

Ejemplo 18: Bacarisse, Heraldos II, cc. 63-64

El tercer movimiento, Lía, se distingue de las composiciones impresionistas de Bacarisse (incluidas las obras orquestales) ${ }^{29}$ por presentarse por vez primera en su obra una melodía autónoma, desligada de la estructura vertical que queda en un segundo plano al armonizar a la voz superior, cuyos rasgos principales son cantabilidad, variabilidad rítmica y sonoridad modal (véase ejemplo 14). No obstante, también en esta breve pieza final de Heraldos el tratamiento motívico es escaso al limitarse el compositor en las dos variantes melódicas (cc. 712 y 13-19) a la conservación de los rasgos diastemáticos y rítmicos más llamativos, sobre todo del impulso sincopado de la cabeza. Solamente en una ocasión, en el Poco piu lento (cc. 20-25) que conduce hacia la recapitulación del tema, se establece un motivo con identidad propia, conducido en tríadas paralelas, cuyo material sonoro de cuarta ascendente y descendente se deriva de forma comprimida del antecedente de la melodía y que a continuación será ampliado paulatinamente.

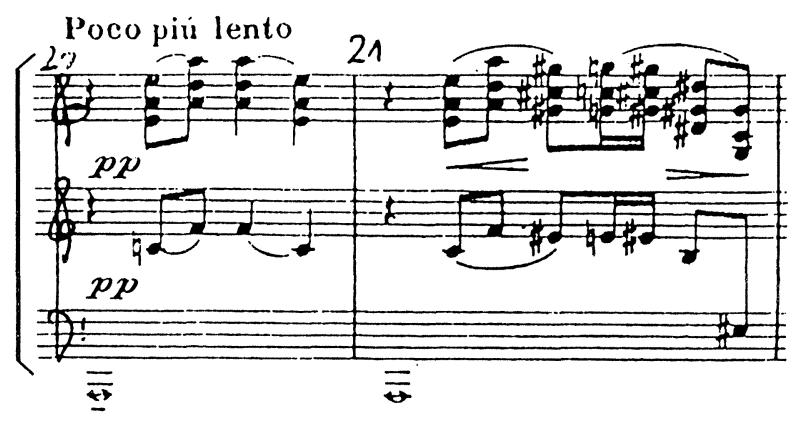

Ejemplo 19: Bacarisse, Heraldos III, cc. 20-21

29. HeINE, op. cit, pp. 110-114. 
El tratamiento melódico observado en la Sonata en fa menor de Arregui y en Heraldos de Bacarisse, que, conforme con la estética impresionista, prescinde de elaboraciones motívicas, se diferencia considerablemente del procedimiento de Turina, en cuya Sonata fantasía la melodía es producto de un cuidadoso proceso continuo de derivación y adición a que están sometidos ciertos motivos principales (véase ejemplo 2). Ya en el primer compás se observan múltiples relaciones entre la estructura horizontal y vertical así como de índole diastemática y rítmica. El primer acorde, formado de dos quintas (re $\rightarrow$ mi), contiene el material sonoro del motivo principal que despliega en sentido descendente una quinta dividida en dos intervalos de segunda y cuarta, los cuales, al igual que la quinta, son esenciales en cuanto al siguiente transcurso melódico. Su decidido ritmo saltadizo que reposa en una blanca está invertido por la mano izquierda, complementándose de este modo el carácter yámbico del motivo principal con la acentuación trocáica de su contrapunto, el cual convierte además la nota de reposo en una variante aumentada del ritmo del motivo de cabeza, cuyo intervalo inicial de segunda mayor imita reiteradamente. Tras una repetición del primer compás, el modelo rítmico del contrapunto pasa a la mano derecha que invierte el primer intervalo a la vez de incrementarlo en una tercera menor, con lo cual se extiende el ámbito melódico de este nuevo motivo a una cuarta. Desde el reposado acorde final del antecedente (c. 5) se desprende en la mano izquierda un motivo transitorio de tresillo que, tras secuenciar el intervalo inicial de segunda mayor, enlaza mediante un salto de quinta descendente con el consecuente. A continuación de la doble recapitulación de la modificada cabeza (motivo principal armonizado y en posición aguda), la mano derecha pasa a una variante rítmico-diastemática del compás 3 (c. 8) que reposa en el compás siguiente, independizándose por siguiente las últimas dos notas en la anacrusa procataléctica, cuyo salto concluyente de tercera a su vez da lugar al último motivo que, igual que el motivo inicial, abarca el ámbito de una quinta descendente.

El estudio del tratamiento motívico en la introducción de la Sonata fantasía hace patente el concepto melódico de Turina, que se basa, de acuerdo con las exigencias estructurales de la forma sonata, en el principio de la «derivación contrastante», lo cual revela influencias de origen germánico en el compositor español. De esta manera, el cantable primer «tema» de la exposición del Allegro molto moderato (cc. 15 ss.) no sólo se deriva del motivo principal de la introducción sino la insistencia en el intervalo de segunda también hace recordar su contrapunto, a la vez que el ostinato del acompañamiento reanuda de manera desplegada el inicial sonido de quintas (véase ejemplo 12). Sin embargo, pese al procedimiento de derivación motívica, los «temas» de esta sonata quedan fragmentarios a consecuencia de la yuxtaposición de sus frases, integradas generalmente por dos compases, que se siguen de forma repetida, secuenciada o modificada. Esta cualidad aditiva de sus temas está aprovechada por Turina en ambos movimientos de la sonata para la interpolación de figuraciones atemáticas, típicas de la estructura horizontal impresionista.

Las ornamentaciones aplicadas por Arregui, Bacarisse y Turina en las respectivas composiciones tienen similares características por tratarse principalmente de rápidos motivos repetitivos con un movimiento mayoritariamente circular, que están deducidos del respectivo campo 
sonoro trasladado a la estructura horizontal a través de arpegios, y cuyo cometido es de índole tanto colorística como virtuosista.

Arregui aplicó las figuraciones solamente en la parte formal que constituye el clímax del primer movimiento con el fin de subrayar la importancia de la melodía a la vez de incrementar la tensión (véase ejemplo 15). Pero si en la primera aparición (cc. 38-43) los triádicos ornamentos de fusas, derivados de la armonización melódica, sirvieron de puro adorno adicional, en la prolongada recapitulación de esta sección (cc. 77-85) éstos cobran protagonismo al pasar a la mano derecha, independizándose a la vez que la melodía se retira paulatinamente, dejando en la mano izquierda sólo una variante del melódico tetracordo inicial.

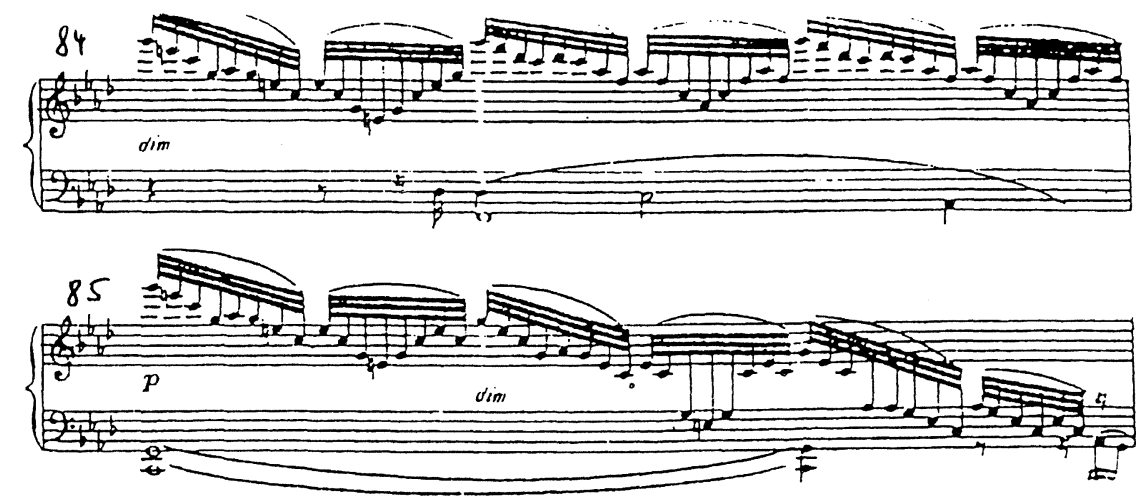

Ejemplo 20: Arregui, Sonata en fa menor I, cc. 84-85

Es semejante la función intensificadora de las figuraciones de nonillos en Helena de Bacarisse, en cuyo centro formal la mano derecha despliega aquel acorde de tres cuartas continuas que determinan el acompañamiento de las partes extremas de este movimiento (véase ejemplo 3), formándose una célula de cuatro notas que, convertida mediante repetición y octavación en un ornamento circular, parafrasea una variante ampliada del tema (cc. 30-46).

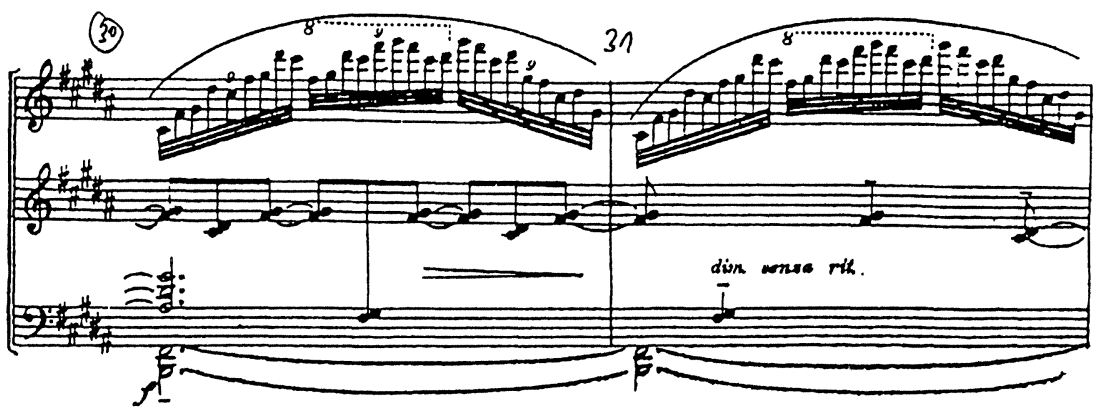

Ejemplo 21: Bacarisse, Heraldos I, cc. 30-31 
En Makheda, la estructura sonora se interrumpe precisamente en los puntos de reposo melódico (cc. 5, 8, 12-13) al introducirse ornamentos circulares de diferentes tríadas menores y mayores (en parte con séptima), emanados de un pedal (la) que mantiene el nexo armónico con la tonalidad principal (la mayor; véase ejemplo 5, c. 5).

En el primer movimiento de la Sonata fantasía de Turina la utilización de un ornamento de sextillos - rítmicamente introducido en el breve puente hacia la reaparición del fragmentario primer tema ( cc. 92-93) - forma parte del proceso de desarrollo al ser atajado la fluidez del tema principal por un arpegio ondulante, cuya interválica recuerda el motivo inicial (sol-fa-do), anunciándose con ello la posterior transformación temática.

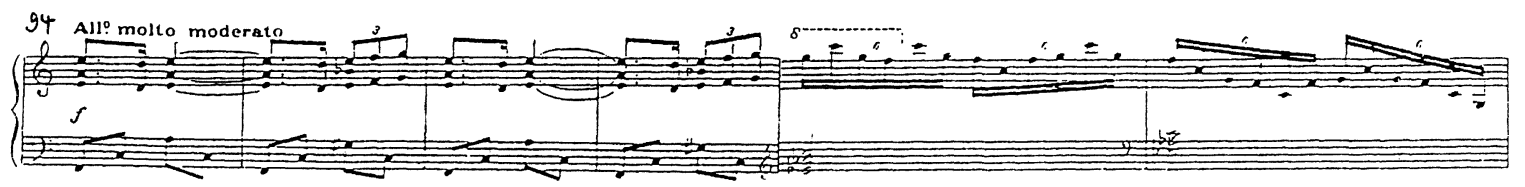

Ejemplo 22: Turina, Sonata fantasía I, cc. 94-99

Además de la esporádica interpolación de estas figuraciones, Turina les concedió un espacio más extenso en un pasaje transitorio de la misma sección de desarrollo, que sirve para enlazar el primer tema con fragmentos del segundo, utilizando, con fines virtuosistas, una amplificación de la anterior figuración (tres quintas en vez de dos) que, tras múltiples reiteraciones en la misma posición, se extienden sobre tres octavas, a semejanza del ejemplo de Helena de Bacarisse con el cual comparten la configuración del material sonoro (véase ejemplo 21).

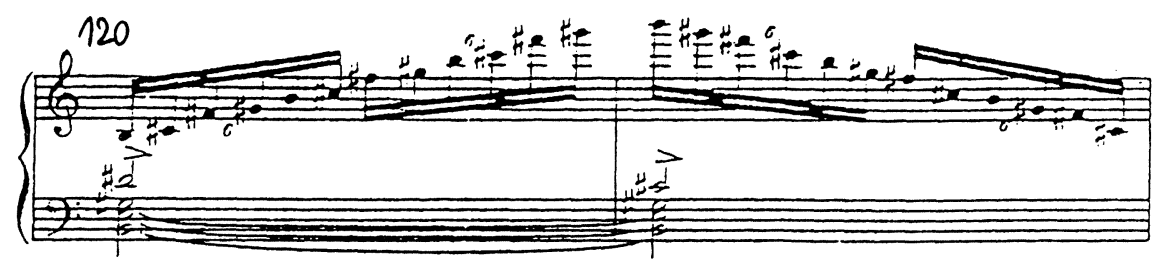

Ejemplo 23: Turina, Sonata fantasía I, cc. 120-121

La semejanza sonora entre algunos fragmentos de Heraldos y la Sonata fantasía además tiene su razón en la común estructura pentatónica de algunos miembros melódicos, que es otro criterio estilístico significativo del impresionismo musical caracterizado por la exploración de efectos sonoros extraños. Mientras Arregui renunció en su Sonata en fa menor a este medio de composición, tanto Bacarisse en Lía como Turina en el primer movimiento combinaron, según el modelo impresionista, la escala pentatónica con acordes paralelos, con el objetivo de intensificar la extrañeza de su cualidad sonora. En Lía la introducción de la pentafonía forma parte de la pri- 
mera transformación del tema (cc. 7 ss.) que ocupa un lugar secundario al desplegarse en posición media entre las tríadas de una doble mixtura modal. Su desplazamiento horizontal produce una nueva melodía pentatónica, cuya particular naturaleza queda reforzada a través del movimiento paralelo de quintas.

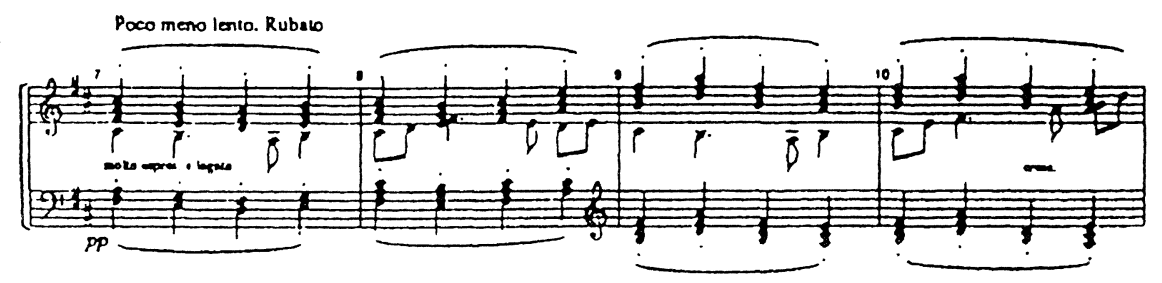

Ejemplo 24: Bacarisse, Heraldos III, cc. 7-10

Del mismo modo, en la introducción de la sonata de Turina la pentafonía en unión con quintas paralelas determina la imagen sonora del antecedente, cuya textura polifónica ocasiona la interacción de dos escalas pentafónicas que distan una quinta (véase ejemplo 2).

\section{Asimilación de los criterios estilísticos impresionistas y estilo personal}

Tras el examen de los criterios estilísticos más importantes del impresionismo musical y su aplicación en las citadas composiciones de Arregui, Bacarisse y Turina, queda por investigar en que medida los tres músicos supieron asimilar estas técnicas en las respectivas obras y adaptarlas a su propio estilo personal.

El estilo de composición en el primer movimiento de la Sonata en fa menor de Arregui se define por el antagonismo entre las estructuras horizontal y vertical en lo que al material compositivo y su tratamiento se refiere. La armonía, extremadamente cromática a consecuencia de la colocación de notas secundarias y del reiterado uso de bordaduras semitonales inspiradas en el intervalo concluyente del motivo principal de la melodía, está tratada con gran soltura en lo cual resalta que, pese a la preponderancia de acoplamientos sonoros afuncionales, el compositor procuró con mucha frecuencia enlazar los diferentes fragmentos formales a través de giros cadenciales basados en parentescos de quinta que evocan efectos funcionales al establecer de esta manera los respectivos centros tonales.

Frente al cuidadoso tratamiento de la armonía, la estructura horizontal ostenta en Arregui una cierta pobreza en cuanto a los medios de composición, no solamente debido a la escasez del material sonoro, restringido a un tetracordo frigio y sus derivados, sino sobre todo a causa de la ausencia tanto de recursos contrapuntísticos como de procedimientos de elaboración motívica sustituidos por otros principios de construcción melódica que estriban en la repetición y secuen- 
ciación. Aunque Arregui iniciara el primer movimiento con una triple exposición del motivo principal, el verdadero protagonista de este tiempo lento es la armonía, lo cual se traduce en el macizo estilo pianístico, esencialmente acordal y aflojado solamente en un fragmento polifónico en el centro de la composición, que pone de manifiesto el profundo arraigo del músico con el estilo sinfónico. La tardanza en establecerse paulatinamente el afuncional ambiente sonoro durante los primeros compases es paradigmática respecto a la moderación con la cual empleó Arregui los recursos impresionistas, que en el caso de la sonata sobre todo cumplen funciones estructurales dentro de la forma palindrómica basada en los principios de yuxtaposición, aunque, no obstante, también contribuyan a evocar el ambiente tétrico que junto con la pausada agógica corresponde a la inicial indicación de «Lento y triste a modo de marcha fúnebre».

En Bacarisse, la aplicación de las técnicas de composición impresionistas está estrechamente vinculada a su inclinación de traducir fuentes extramusicales a la música, sirviéndole, en su obra temprana, la combinación de los distintos criterios estilísticos de recurso para evocar los típicos efectos impresionistas de «Tonmalerei» (pintar con sonidos). El carácter de las tres piezas de Heraldos, compuestas veinte años después de la sonata de Arregui, se ajusta al contenido del correspondiente verso de su modelo literario, por lo cual los medios de composición del impresionismo se utilizan principalmente con fines ilustrativos, si bien el cambio de combinaciones estilísticas además contribuya a determinar la respectiva forma. Es significativo el tratamiento antitético de los primeros dos movimientos, que sugieren los imágenes del «blancor de un cisne» y de «un pavo real», respectivamente, ${ }^{30}$ cuyo distintivo más eminente es el concepto de contraste, oprimido en el tranquilo primer tiempo y realzado en el animado segundo, que se caracteriza por la continua alternancia de nuevas ideas musicales. La homogeneidad de Helena se debe a la restricción del material compositivo que estriba principalmente en sonidos de cuarta y en tresillos sincopados. Estos elementos básicos, a semejanza de la sonata de Arregui, tampoco en Bacarisse están sometidos a un tratamiento de elaboración motívica al reaparecer sólo con un semblante modificado y en combinaciones diferentes. Un rasgo singular es la función ambigua de la estructura sonora que no solamente sirve de sostén armónico sino también determina, a través de su desplazamiento horizontal, la fragmentaria melodía, a la vez de fomentar, en forma de arpegios, la virtuosidad de la sección central.

Una comparación de Helena con La cathédrale engloutie de Debussy (Préludes, vol. 1/X) hace patente una serie de afinidades, sobre todo en cuanto a la estructura sonora y rítmica, sujeto a la respectiva idea extramusical, que ponen de manifiesto la estrecha ligazón de Bacarisse con su modelo francés. Ambas composiciones comparten el concepto formal en cinco secciones, el tempo tranquilo y la dinámica modesta, además de la tendencia ascendente de la línea melódica en las respectivas secciones externas, la que en las respectivas obras transcurre con un ritmo uniforme dentro de un compás ternario (Debussy: 6/4 y 3/2; Bacarisse: 3/4). Además de todo ello, ambos compositores utilizaron un pedal de similares características (Debussy: quintas; Bacarisse:

30. Véase anotación 19. 
cuartas) que en el preludio de Debussy, quien indicó su significado extramusical [Profondément calme (Dans une brume doucement sonore)], suscita en forma de campanadas los recuerdos de la «catedral sumergida», conforme con el título. Bacarisse, a su vez, se mostró autónomo en el tratamiento del pedal, descompuesto rítmicamente en tresillos sincopados, el cual hace pensar, de acuerdo con el patrón literario, en el monótono movimiento de natación de un «cisne», cuyo aspecto majestuoso se refleja en el sosegado curso de las cuartas paralelas de la melodía.

La atmósfera de Makheda que está ligada a la imagen del irisado y versátil pavo real, se evoca a través de múltiples efectos de «Tonmalerei», cuyo continuo cambio origina una fuerte agitación. Un papel importante en la creación de impresiones instantáneas desempeña el concepto formal, basado en la fragmentación estructural y el contraste, al atribuir el compositor una desigual importancia a los componentes de índole sonora, melódica o puramente ornamental, lo cual tiene influencia sobre la técnica pianística en cuanto a textura, espacio sonoro, agógica y dinámica de las siete secciones (más la Coda). A semejanza de la sonata de Arregui, también en Makheda el tratamiento pianístico revela el verdadero origen del pensamiento musical de Bacarisse fundado en el volumen orquestal, manifestándose en el hecho de que el compositor, al no llegar con dos sistemas, solía utilizar tres. ${ }^{31}$

Contrariamente a las respectivas obras de Arregui y Bacarisse, la Sonata fantasía de Turina es sumamente pianística, concebida en gran parte horizontalmente, lo cual se pone de relieve a través del diálogo entre ambas manos establecido desde los primeros compases. Esta importancia que Turina achacó a la estructura melódica tiene consecuencias en su principio de composición, opuesto al de sus antecesores, por estribar en la derivación contrastante. La elaboración motívica, antiimpresionista por naturaleza, es una de las características más significativas del estilo personal de Turina en esta sonata combinada preferentemente con aquellos medios estilísticos del impresionismo que intervienen en la imagen sonora, predominando los recursos arcaicos como modalidad, bordón y pentafonía, los cuales están «modernizados», según el criterio impresionista, a través de progresiones afuncionales, movimiento paralelo de las distintas voces, colocaciones de notas secundarias y estratificaciones de terceras y quintas. Destaca la peculiaridad de que, al contrario de la respectiva obra de Bacarisse y, de forma más moderada, también de la de Arregui, en la Sonata fantasía de Turina los medios estilísticos del impresionismo no suelen utilizarse con un fin ilustrativo, sino cumplen por lo general un cometido funcional en cuanto a la forma de sonata. De este modo, la típica ornamentación impresionista no aparece sino en la parte central donde, en sustitución a las tradicionales técnicas de desarrollo temático, contribuye primero al fraccionamiento del tema principal, independizándose luego como elemento virtuosista cuya reiterada circulación sobre notas alternadas de pedal retiene durante un instante el adelantamiento del «desarrollo», antes de que enlazara con el fragmentario segundo tema. Por último merece atención de qué manera compaginó Turina las técnicas de composición impresionistas con su profundo andalucismo al fundir los rasgos comunes de ambos, según ocurre con el

31. Este hecho da la razón por qué Bacarisse realizó de Heraldos distintas versiones instrumentales, entre ellas una para gran orquesta. 
modo frigio - muy en boga entre los compositores impresionistas-, el cual está combinado, en la introducción de la sonata, con una variante singular de la cadencia andaluza. En el primer movimiento del Opus 59 el origen de la sonoridad preponderante de quinta vacía y de ciertas fórmulas rítmicas, sobre todo de tresillos, es ambiguo puesto que se trata de características enraizadas tanto en la música impresionista como en el folklore andaluz. Sin embargo, así como están utilizados ciertos criterios de composición puramente impresionistas, también existen rasgos estilísticos de proveniencia exclusivamente andaluza, como los giros melismáticos en la melodía del segundo movimiento, típicos del flamenco. En vista al cuidadoso tratamiento formal que, al estribar en la premeditada aplicación de los diferentes criterios estilísticos, procura establecer relaciones no solamente entre motivos individuales y secciones enteras sino también entre los dos movimientos de la obra con el fin de conseguir una unidad cíclica, parece acertado que Turina retirara el título original de Sonata andaluza sustituyéndolo por el actual de Sonata fantasía. ${ }^{32}$

\section{Conclusiones}

El estudio de las técnicas impresionistas en tres obras de Arregui (1902), Bacarisse (1922) y Turina (1930) que abarcan un período de casi treinta años, pone de manifiesto que en la música española el impresionismo con sus particularidades estilísticas fue más que una corriente de moda meramente pasajera al influir sobre dos generaciones de compositores.

Aunque distando tres décadas, las obras analizadas de Arregui y Turina, ambos representantes de la misma generación, ostentan semejanzas en cuanto al moderado uso de las técnicas de composición impresionistas y a la perseverancia en algunos procedimientos arraigados con la tradición clásico-romántica. Mientras sobre todo el tercer movimiento de la Sonata en fa menor de Arregui es un producto típicamente decimonónico, el primer tiempo, compuesto poco después de comenzar el siglo xx, ofrece una sorprendente modernidad junto a una gran soltura armónica, poco habitual en un compositor español del tardío siglo xıx, por lo cual debe considerarse una pieza clave en la historia de la música española de aquella época. Por falta de acceso a su obra sinfónica, actualmente es imposible averiguar en qué medida el impresionismo impregnó posteriores obras suyas, aunque las observaciones de Marco, ${ }^{33}$ quien sólo destaca las características románticas y nacionales en la música de Arregui sin mencionar su inclinación impresionista, hagan sospechar el que referente a su única sonata para piano se trate de un dichoso caso aislado por compenetrarse de forma única la ingeniosidad y la imaginación creadora del compositor.

Turina a su vez compuso su Sonata fantasía en plena madurez después de haber experimentado durante aproximadamente quince $\operatorname{años}^{34}$ en géneros musicales muy dispersos las técni-

32. Según Iglesias, op. cit., p. 325.

33. MARCo, op. cit., pp. $68 \mathrm{~s}$.

34. Benavente, al estudiar el impresionismo en Turina no fecha las respectivas obras, aunque por la mención de Niñerías op. 21, editadas en 1918, se deduce que el interés del compositor en las técnicas impresionistas de composición coincide con su retorno a España. (Véase Benavente, op. cit.) 
cas de composición impresionistas, las cuales asimiló fundiéndolas con criterios estilísticos originarios del folklore andaluz además de combinarlas con procedimientos melódicos y formales aparentemente incompatibles con la idea impresionista, con el resultado de conseguir un inconfundible estilo personal que en el primer movimiento de la sonata se hace patente a través de un modernismo algo arcaico.

La moderación en la adopción de determinados medios impresionistas en las dos sonatas, explicable en el caso de Arregui con la fecha reciente de las innovaciones estilísticas y en Turina con la madurez de su estilo personal, contrasta con la exuberancia de estos recursos aplicados por Bacarisse en las tres piezas de Heraldos. Pero aparte de demostrar gran habilidad e ingenio al combinar los diferentes criterios estilísticos del impresionismo, Bacarisse no supo desprenderse de sus modelos franceses, lo cual le impidió crear su propio estilo personal. Por eso no es de extrañar que en su posterior producción, tras un silencio de tres años (1923-1926), Bacarisse se apartara completamente del impresionismo musical, aunque conservara, de forma modificada, algunos de sus recursos de composición más eminentes. ${ }^{35} \mathrm{~A}$ falta de testimonios al respecto, las razones de tal denegación sólo pueden sospecharse, pero la más probable es que el compositor hubiese llegado a la convicción de encontrarse, como epígono de Debussy, en un callejón sin salida, siendo posible una continuación de su evolución artística únicamente al emprender un camino opuesto. En la decisión de Bacarisse de cambiar su estilo, también debe haber influido su carácter, dominado menos por el intelecto que por las emociones, que tendió, según demuestran sus posteriores composiciones, al desenvolvimiento melódico, por lo cual tenía que resignarse, con el tiempo, a una estética musical basada, como la impresionista, principalmente en efectos sonoros.

Si bien Bacarisse se entregó en el primer período de su trayectoria artística exclusivamente a las innovaciones impresionistas a la vez de evadir cualquier aproximación al nacionalismo musical de proveniencia española, en Turina (a semejanza de Falla) ocurrió todo lo contrario por encontrar sus raíces españolas a través del impresionismo. Sin embargo, pese a su asimilación de la música francesa, no puede considerarse a Turina un «compositor impresionista» debido al «realismo ibérico» que emana de sus respectivas obras y que, según las observaciones de Rodolfo Halffter en Falla, «nada tiene que ver con la fantasmagoría sensual de Debussy». ${ }^{36}$ Desde este punto de vista, sin duda, Heraldos de Bacarisse es la más impresionista a la vez que la más vanguardista de las tres obras analizadas, aunque, debido a su exclusividad estilística y su dependencia del modelo, también es la menos personal.

35. HeINE, op. cit., pp. 142-157.

36. Halffter, Rodolfo. «Manuel de Falla y los compositores del Grupo de Madrid de la Generación del 27 [Lección Magistral, Madrid 21-VI y 10-VII-1976].» Rodolfo Halffter (su obra para piano). Coord. Antonio Iglesias. Madrid: Alpuerto, 1979, p. 53. 